\title{
DA "REVOGAÇÃO" DO PRINCÍPIO DA FUNÇÃO SOCIAL DOS CONTRATOS: REFLEXÕES SOBRE A APLICAÇÃO JURISPRUDENCIAL DO ARTIGO 421 DO CÓDIGO CIVIL E SUA INTERFACE COM O DEVER DE FUNDAMENTAÇÃO DAS DECISÕES JUDICIAIS
}

\author{
Rogério Gesta Leal ${ }^{1}$
}

Bruno Hermes Leal

\section{RESUMO}

O artigo colima estabelecer uma relação entre o princípio da função social do contrato, insculpido no artigo 421 do Código Civil brasileiro, sua aplicação jurisprudencial e o dever constitucional de fundamentação das sentenças judiciais. A primeira parte volta-se à análise da configuração histórico-dogmática do princípio da função social do contrato, perpassando o contexto de passagem do Estado liberal para o Estado social, frisando as modificações daí decorrentes na principiologia clássica do contrato. O autor analisa as possíveis relações do cerne filosófico do artigo $421 \mathrm{com}$ os princípios de solidariedade social e socialidade, haja vista que o mesmo se encontra sob a égide da Constituição federal de 1988 e o Código Civil de 2002. Na segunda parte, procede-se a uma tentativa de contorno dos caracteres precípuos do princípio da função social do contrato, máxime suas perspectivas interna e externa. Por fim, a terceira parte dedica-se à revista da jurisprudência recente dos principais tribunais do país e como sua abordagem, com maior ou menor rigor científico, contribuiu para a definição do conceito da função social do contrato e legitimou-se através da devida fundamentação.

Palavras-chave: Dever de fundamentação. Função Social do Contrato. Jurisprudência. Princípios contratuais.

\section{INTRODUÇÃO}

A temática do direito contratual, ou mesmo da figura pura do contrato, continua suscitando polêmica derredor suas características e princípios fundamentais. Quase como símbolo da autonomia dos indivíduos frente ao Estado, a figura do contrato não se restringiu a permear a grande maioria de todas as relações privadas, assumindo papel de principal veículo de comunicação entre os sujeitos e seus patrimônios; o instituto imiscuiu-se até na sua antiga antípoda, o Direito Público. ${ }^{3}$

Hodiernamente, em uma sociedade transnacional, em que a "realidade presente é sempre mais mutante no tempo e sempre mais uniforme no espaço", a importância da figura do contrato avulta como principal instrumento de flexibilização a adaptação dos interesses individuais face ao engessamento das legislações codificadas. ${ }^{4}$

A discussão das questões atinentes às origens e aplicações do princípio da função social do contrato, e a importância que se deve dispensar à correção jurídica e precisão conceitual quando no trato delas, tem sua importância sensivelmente 
aumentada face ao artigo 421 do novo Código Civil brasileiro, quando vincula o exercício e fundamento da "liberdade de contratar" ao princípio em tela.

Face ao novo dispositivo legal, tem havido celeuma jurisprudencial porquanto se, de um lado, o legislador forneceu valioso argumento para os advogados na defesa de seus clientes, de outro, ensejou difícil situação dos juízes aquando da aplicação de um conceito que é avesso a definições exaustivas. Tal é a situação que, em muitos acórdãos dos principais tribunais do país, encontramos patente confusão entre princípios distintos (entre eles 0 da boa-fé e os seus desdobramentos), os quais são aplicados aleatoriamente, em "conjunção" estranha com o princípio da função social, acabando por reduzir a zero sua eficácia própria, restando obnubilada a "voz própria e específica do artigo 421"5

Para que possamos proceder, na terceira parte de nosso trabalho, à análise jurisprudencial a que nos propusemos, impende, preliminarmente, recuar alguns séculos a fim de assentar, em apertada síntese, algumas premissas filosóficodogmáticas da formação contratual clássica (primeira parte) e no seu desdobramento rumo à função social do contrato (segunda parte).

Tal é a metodologia que consideramos adequada para tornar mais evidente, ao final deste pequeno espaço de reflexão, a recíproca implicação em que se encontram o instituto jurídico da função social do contrato e o plexo sociológico da necessidade de segurança - aqui especificado em demanda pública pela fundamentação das sentenças judiciais.

\section{A FUNÇÃO SOCIAL DO CONTRATO: ADVENTO DE NOVO PARADIGMA NA DOGMÁTICA CIVILÍSTICA}

A análise de qualquer instituto jurídico com alguma tradição dentro do Direito Privado reporta, necessariamente, às suas origens romanas. A noção de contrato romana - no período justinianeu - era uma das quatro fontes de obrigações ${ }^{6}$, sendo, àquela época, bem mais restrita que a noção hodierna. Fiéis a uma conjuntura eminentemente formalista, os juristas romanos clássicos acreditavam que o contractus não se vincula ao acordo de vontades (sendo os pactum oriundos desse fato, razão pela qual não geravam obrigações), senão a uma forma rígida. ${ }^{7}$

A recepção operada pelos juristas medievais manteve as características da relação contratual no decorrer da grande maioria da Idade Média. ${ }^{8}$ Restaram virtualmente intactos os aspectos que aqui pretendemos ressaltar, quais sejam as noções de vinculatividade do contrato e o seu entendimento como "coisa das partes", na qual não estariam envolvidos quaisquer terceiros.

Interessa-nos aqui, contudo, o período subseqüente: 0 advento das Revoluções Liberais correspondeu a uma identificação de um valor político a outro valor filosófico, qual seja, a da liberdade e dignidade do homem, tendo nestes pressupostos, o grande valor de sua vontade. O voluntarismo, apesar de ter seu cume restrito ao advento do século XIX, é um termo filosófico de fundas raízes históricas, remontando a Aristóteles e Guilherme d'Occam, ainda que associadas à noção de razão. ${ }^{9}$ 
O contrato está sujeito, tal como o Direito em si, à compreensão histórica, típica das ciências do espírito. Encontra-se inserido em determinada sociedade, que tem concepções variáveis, tal como variável é a História. Como bem observa Enzo Roppo, a compreensão do contrato não pode esgotar-se na dimensão jurídica, porquanto sua existência não é autônoma, estanque nos livros de Direito. ${ }^{10}$ Assim, a noção do contrato foi, também, impregnada do movimento filosófico que lhe servia como "pano de fundo" histórico, como realidade que restava subjacente, determinando a forma como seria delineada a relação contratual. ${ }^{11}$

O advento da primeira grande codificação, o Código Civil francês de 1804, consolidou o ideal de uma codificação abarcante, derivada da razão humana, perfeita para um Estado ideal, para o homem abstratamente livre e digno, o qual podia, tal como o Fausto de Goethe, exclamar: Bin ich Gott? ${ }^{12}$

Na letra fria do seu artigo 1.134, o Code Napoleon consagrou lapidarmente o princípio da obrigatoriedade dos contratos, afirmando seu caráter de lei para as partes que, livremente, os formaram. Os eventos históricos seguintes, nada obstante, souberam cobrar do Direito respostas às novas exigências sociais.

\subsection{Das modificações dos princípios reitores da concepção clássica do contrato}

Constatou-se que, na sociedade industrial, a auto-regulação dos processos econômicos - pressuposto do liberalismo setecentista - não prosperava: a sociedade, abandonada a si própria, engendrava severas desigualdades. O contrato, como instrumento que é, foi plasmada para diferentes circunstâncias. Nesse contexto, a liberdade sem freios esmagava outros valores humanos, tão fundamentais como ela própria. Concretizava-se a profecia do Padre Lacordaire: "Entre le fort et le faible, c'est la liberté qui opprime et la loi qui affranchit ».

Da conjugação dessas experiências havia de nascer como tarefa do Estado velar por um equilíbrio adequado entre os poderes sociais, reagir contra processos de concentração, impedir abusos de posições de poder, garantindo uma harmonização adequada dos interesses conflitantes. ${ }^{13} \mathrm{Na}$ percuciente análise do professor Galgano, há uma mudança de perspectiva com relação ao Estado, de uma entidade necessariamente alheia ao processo de satisfação das necessidades privadas passa-se ao entendimento de que ao Estado devem ser cometidas tarefas de realização do bem-estar dos cidadãos em setores considerados fundamentais, prioritários, vitais, ao mesmo tempo que lhe incumbe intervir nas relações interindividuais de forma a, pelo assegurar de valores mínimos de convivência, corrigir as conseqüências que a situação real de desigualdade dos sujeitos acarreta. $^{14}$

A partir desse novo contexto, a doutrina começa a demonstrar uma distinta orientação: dissertam sobre a nova feição contratual nomes como o de Louis Josserand $^{15}$, Enrico Cimbali $^{16}$, Karl Renner ${ }^{17}$. É a partir de uma nova abordagem doutrinária, igualmente, que se vão aproximar os pólos do direito privado e direito público, a mais tradicional dicotomia do Direito, fenômeno particularmente perceptível na análise a que aqui nos dedicamos, cujo exame é objeto da próxima subseção. 


\subsection{Da função social do contrato e a Constituição de 1988}

A constatação de que um princípio concernente à seara civil sofra o influxo de um princípio constitucional remete, inexoravelmente, à reflexão sobre o esmaecimento da linha que costumava ser apontada como divisória entre o Código Civil e a Constituição. Deveras, passando por diferentes estágios - variando entre os extremos do primado do privado sobre o público e o primado do público sobre o privado -, a referida dicotomia encontra-se esmaecida, permeada pela comunicação recíproca de princípios e instrumentos. ${ }^{18}$ Tal como 0 Estado assume, em determinadas relações, a posição de mero contratante, também o instituto do contrato, inobstante ter assistido à publicização de seus princípios mais tradicionais, tem seu lugar na "revanche", na privatização do direito público, assumindo distinta função, como atestam os expressivos exemplos supracitados do professor Galgano.

É necessário frisar, neste sentido, a importância da comunicação do Direito Civil com a Constituição, subordinado a esta, albergando seus princípios e, em última análise, seus valores. Tal é, em apertada síntese, o "escudo" da escola do Direito Civil-Constitucional: a começar pela restrição (ou funcionalização) da autonomia privada $^{19}$, a Constituição transmite ao Código Civil - e daí, vinculando todas as relações privadas sob sua égide - o maior valor da proteção à dignidade da pessoa humana do que ao seu patrimônio; da preservação de alguns valores que devem ser levados em maior conta do que o interesse singular. ${ }^{20}$

Na senda desta comunicação entre os âmbitos público e privado, pode-se lobrigar a relação direta entre a função social do contrato e o valor da solidariedade social, referido no artigo $3^{\circ}$, I da Constituição Federal. ${ }^{21}$ Em interessante relação com a perspectiva de Émile Durkheim - o qual imputa, às sociedades primitivas a solidariedade mecânica, em que se depende com naturalidade uns dos outros; e às sociedades avançadas, a solidariedade orgânica, que reluta em admitir que depende - escreve Luis Renato Ferreira da Silva que, com a idéia de constitucionalização do direito privado, é impensável que um dos objetivos fundamentais da República não vá influenciar nas relações privadas dos indivíduos. ${ }^{22}$

\subsection{Da função social do contrato e o Código Civil de 2002}

Estabelecidas as premissas que permeiam a nova civilística, orientada que é pelos valores extraídos da Constituição Federal de 1988, podemos, ainda, proceder a uma análise da inserção desse princípio dentro do próprio Código Civil, o qual, certamente, não instituiu a função social, tendo-a elevado à categoria de princípio regente de todo o direito contratual. ${ }^{23}$

Tendo já apresentado sua inclinação claramente "social" e em consonância com os dispositivos constitucionais no que tange à ordem econômico-social, há que se frisar duas características principais do novo diploma civil que hão de influenciar na compreensão do princípio da função social, quais sejam, as cláusulas gerais e as diretrizes axiológicas fundamentais. 
Com relação à segunda, convém frisar a diretriz da socialidade, a qual se traduz no esforço do legislador de superar o caráter individualista, apanágio da época do antigo Código, impondo funções aos modelos jurídicos e o compromisso deles com a coletividade. Instrumentaliza-se, portanto, o contrato (art. 421) e a propriedade (art. 1.228), em simbólica migração da visão liberal-individualista para uma perspectiva social-humanista dos institutos. ${ }^{24}$

Já no que tange a técnica das cláusulas gerais, estas coadunam-se com a concepção de um sistema aberto, móvel, que não se encontra coarctado ao restrito mundo jurídico. A cláusula geral reenvia o jurista, da lei, à análise do mundo real, recepcionando: a) conhecimentos de outros campos (assim, da Ecologia - na análise da função ambiental do contrato -, da Sociologia, da Economia - na análise dos impactos "em cadeia" que o contrato pode gerar), em ligação extra-sistemática; b) também, em ligação inter-sistemática, recolhendo da Constituição o seu norte de "solidariedade" 25

Em especial atenção à utilização das cláusulas gerais, e ser a norma do artigo 421 perfilhada a esta categoria, é que impende aqui a análise com relação à fundamentação jurídica de sua aplicação.

\section{O ESBOÇO DO CONCEITO DE FUNÇÃO SOCIAL DO CONTRATO}

Tentando delimitar o conceito de "função social do contrato", a doutrina tem-se inclinado para uma divisão bastante didática, porquanto facilita o papel de legitimação das decisões jurisprudenciais, ao passo que vai sistematizar seus argumentos. Assim, parece-me razoável cindir os efeitos da função social do contrato em dois ramos principais: nas eficácias intersubjetiva (ou função interna) e transubjetiva (um função externa). ${ }^{26}$

\subsection{Dos efeitos internos ou da eficácia intersubjetiva}

$\mathrm{Na}$ sua concepção interna, a função social se expressa na possibilidade da imposição de deveres positivos aos contratantes, pois o direito subjetivo de contratar (na concepção de limites internos) já nasce conformado a certos deveres de prestação.

A eficácia positiva visa impulsionar condutas dirigidas a um ativo favorecimento e promoção de justificados interesses da contraparte, o que vem a adquirir um particular relevo, ainda que não exclusivamente, no domínio das perturbações que possam ocorrer no decurso da execução do contrato. Pode-se exemplificar, na senda da professora Judith Martins-Costa, a eficácia intersubjetiva em três casos principais:

A) Contratos que instrumentalizam a propriedade dos bens de produção: o grupo dos contratos que instrumentalizam a propriedade de bens de produção tem uma interface direta com o princípio da função social da empresa e com o princípio da função social da propriedade. Em ambos os casos a nota dominante é a da prevalência dos valores e interesses comunitários sobre os individuais. ${ }^{27}$ 
B) Contratos que viabilizam, para uma das partes, prestações essenciais: esse tipo de contrato teve sua tipologia estabelecida pela professora Teresa Negreiros, ao considerar como eixo para a concretização da função social não o contrato, instrumento jurídico, mas o objeto (ou bem da vida) que o contrato visa instrumentalizar. ${ }^{28}$

Tanto mais essencial for, para as partes, o bem da vida subjacente ao objeto contratual (como no seguro de vida, no seguro-saúde, no fornecimento de água e energia elétrica, nos transportes), maior deve ser a intervenção estatal (concretizando o princípio da função social), na sua tríplice esfera, para tutelar o bem contratado.

C) Contratos comunitários são aqueles - como os de seguro, de consórcio, de prestação ou fornecimento de serviços de energia elétrica, entre outros - em que subjaz, na sua própria racionalidade econômico-social, a noção de comunidade ${ }^{29}$, uma vez que num dos pólos não está meramente o interesse de uma soma aritmética de individualidades, mas interesses supra-individuais ou coletivos. ${ }^{30}$

\subsection{Dos efeitos externos ou da eficácia transubjetiva}

Graças a concepção tradicional do contrato, como uma relação que vincula só e tão-somente um pólo a outro, restando impossível comprometer terceiros nas suas avenças, é difícil compreender a eficácia de contratos para além de um vínculo bilateral que une indivíduos isolados, cujos interesses são contrapostos. Porém os contratos são, antes de mais, fatos sociais. Em graus e medidas diversas podem afetar - e positivamente afetam - quem deles não tomou parte.

Trata-se, então, de perceber no Direito Contratual os reflexos de um fenômeno bem mais amplo - o fenômeno da transindividualidade - que, no Direito processual contemporâneo tem expressão nos instrumentos que tutelam os chamados interesses difusos e coletivos. ${ }^{31} \mathrm{Na}$ base dessa constatação situa-se a percepção das eficácias transindividuais decorrentes do princípio da função social, cujo inventário ainda se está por fazer, mas que podem ser exemplificadas mediante o recurso a três grupos de situações:

A) Tutela externa do crédito, abrangendo as situações em que um terceiro, que não é parte no contrato, é responsabilizado, perante o credor, por lesar o direito de crédito, ou, noutra perspectiva, por interferir com o contrato. Trata-se aqui, de uma nova abordagem do princípio da relatividade do contrato - como já expusemos acima -, examinando-o à luz da função social do contrato, mas não mais a propósito da extensão da responsabilidade em favor de um terceiro, e, sim, a propósito da responsabilidade de um terceiro que contribui para o descumprimento de uma obrigação originária de um contrato do qual não seja parte. ${ }^{32}$

O caso paradigmático nesse sentido foi a situação dos contratos de exclusividade que as distribuidoras de gasolina mantêm com os postos que exibem suas bandeiras. Nesse sentido, opinou o professor Antônio Junqueira de Azevedo pela responsabilização das distribuidoras que vêm celebrando contratos com os postos vinculados a uma outra distribuidora em termos de exclusividade, sem que 0 
consumidor seja alertado. Em máxima simbólica: "terceiros não podem se comportar com se o contrato não existisse". ${ }^{33}$

B) Contratos com interdependência funcional. . Dizem respeito à consideração da eficácia na esfera de terceiros determinados. A consideração da eficácia de um contrato na esfera jurídica de terceiros, ou em outros contratos, está na continuidade e na interferência entre esferas de interesse, que se congregam, em múltiplas esferas na vida de relações contratuais, por forma a impor aos gestores das esferas contíguas limites internos que, na convivência ordenada e civil, descendem da socialidade. São exemplos os crescentes fenômenos das redes contratuais e das conjugações de interesses rubricados como parcerias, a multiplicação dos grupos societários (formais ou de fato), as associações estratégicas. ${ }^{34}$

C) Extensão da eficácia a terceiros não-determinados e a bens fundamentais da comunidade. Para além de a função social atuar como limite à ação individual em face de direitos e interesses de terceiros, atua também positivamente, impondo deveres de atuação. Como exemplos que de imediato saltam à mente estão os contratos que, de alguma forma, envolvem o meio ambiente e a tutela da concorrência. $^{35}$

Nesse sentido, prevê a nossa Constituição, nos artigos 186, II e 225 a preservação do meio-ambiente, elevando-o à categoria de bem de toda a comunidade brasileira e critério de aferição do cumprimento da função social da propriedade. Infere-se daí que, sendo o meio ambiente ecologicamente equilibrado bem de uso comum do povo (terceiro gênero de bens, nem público nem privado) e essencial à qualidade de vida de todos, não pode o contrato furtar-se de observar tais parâmetros, razão pela qual está adstrito aos limites traçados pela razoável proteção do meio ambiente, considerando, por exemplo, os espaços territoriais especialmente protegidos. ${ }^{36}$

\section{A APLICAÇÃO JURISPRUDENCIAL DO ARTIGO $421^{37}$}

Esboçados alguns contornos principais derredor o conceito de função social do contrato, vejamos como a jurisprudência têm procedido à sua utilização e, mais importante, se tem legitimado de modo a fornecer a devida segurança jurídica aos jurisdicionados, tecendo, antes, alguns comentários sobre o exercício do Poder Judiciário.

\subsection{Da necessidade da fundamentação jurídica}

O Poder Judiciário, contextualizado que deve estar aos consectários filosóficoideológicos do Estado - que além de Direito, é Democrático ${ }^{38}$-, e como "poder" que $\mathrm{e}^{39}$, deve estar constantemente atento ao processo de legitimação frente à sociedade civil.

Ora, reprisando a conceituação weberiana das formas de legitimação de dominação, descartamos prontamente, pois incompatível com a natureza do exercício da jurisdição, as modalidades de dominação tradicional - exercida através 
do simples costume ao obedecer - e carismática - resultante de uma qualidade excepcional do ser dominante, que cativa a subserviência de outrem -, restando tão somente a dominação racional-legal. ${ }^{40}$

Na senda deste raciocínio, se o Judiciário legitima-se através da aquiescência racional dos jurisdicionados, é pressuposto fundamental que declinem em suas manifestações - sejam elas sentenças, acórdãos, etc. - as suas razões determinantes, tal como alvitram os artigos 93, inciso $X$ da Constituição Federal; e o 458, inciso II, do Código de Processo Civil.

Assentes estas premissas, passemos à análise de parcela da jurisprudência que examina a questão da função social do contrato.

\title{
3.2 Da "revogação" do princípio da função social do contrato
}

O termo técnico empregado no subtítulo refere-se ao sentido etimológico, ressaltado por Pontes de Miranda, aquando de sua monumental obra sobre o Direito Privado. ${ }^{41}$ Trata-se a revogação, stricto sensu, da "retirada da voz" (re--vox), isto é, o esvaziamento do conceito, à medida que a jurisprudência tem se mostrado incapaz de fundamentar de forma individual a aplicação princípio.

A título exemplificativo ${ }^{42}$, tomemos dois casos paradigmáticos, por questões de economia de tempo e espaço:

\begin{abstract}
TJRJ - 2007.002.23679 - AGRAVO DE INSTRUMENTO - DES. MARIO ASSIS GONCALVES - DECIMA SEGUNDA CAMARA CIVEL - 10/09/2007. Aplicacão dos princípios da função social do contrato, do equilíbrio contratual, da vulnerabilidade e da boa fé objetiva. Agravo de Instrumento interposto por banco contra decisão que, em ação cautelar, determinou-Ihe a juntada aos autos de todos os extratos referentes ao período contido entre 1987 e 1990 relativamente a eventuais contaspoupança que a autora mantivesse na instituição. Verossimilhança das alegações iniciais, diante da pacífica jurisprudência dos Tribunais Superiores. Período de tempo em que os bancos têm de conservar os extratos. Recurso a que se nega seguimento.
\end{abstract}

Resta evidente, no excerto em questão, o intuito de mera legitimação ao arrolar amplo leque de princípios contratuais, não distinguindo o significado ou o âmbito de eficácia de quaisquer um deles. O efeito acaba por ser diametralmente oposto: queria-se suporte jurídico à sua decisão, conseguiu-se estimular a insegurança dos jurisdicionados, os quais não sabem qual é, efetivamente, a posição da jurisprudência, sua interpretação acerca da autonomia negocial.

De outra banda:

TJRJ - 2007.001.25499 - APELACAO CIVEL - DES. CHERUBIN HELCIAS SCHWARTZ - DECIMA SEGUNDA CAMARA CIVEL - 03/07/2007. APELAÇÃO CÍVEL. NEGÓCIO JURÍDICO IMOBILIÁRIO. RESCISÃO DO CONTRATO. INADIMPLEMENTO DO PROMITENTE COMPRADOR. DEVOLUÇÃO DAS QUANTIAS PAGAS. CABIMENTO. Havendo 
inadimplemento do promitente comprador, impõe-se o acolhimento da pretensão autoral, no sentido de rescindir o contrato celebrado entre as partes. Correta a decisão que determinou a devolução dos valores pagos com o fito de evitar-se o enriquecimento ilícito. Contudo, de acordo com a possibilidade de intervencão estatal com o fito de garantir o equilíbrio da avença, a restituição dos valores deve atender a funcão social do contrato, garantindo a boa-fé dos contratantes (artigos 421 e 422 do $\mathrm{CC}$ ). Recurso parcialmente provido para determinar que a devolução das quantias pagas seja feita em consonância ao disposto neste acórdão

Salvo melhor juízo, o desembargador in casu sugeriu, se não a identidade entre os princípios da boa-fé e da função social do contrato, ao menos o atendimento de ambos - e mais outros objetivos tão-somente nominados, sem qualquer aprofundamento ou distinção - através de seu voto.

Não se trata de tergiversação jurídica: atentemos ao pressuposto hermenêutico de que a letra da lei não contém palavras supérfluas ${ }^{43}$, e não se nos afigura possível a compatibilização entre: a) a existência do artigo 422, a especificar o princípio da boa-fé objetiva em sede de relações contratuais, e do artigo 421 , objeto de nosso estudo derredor a função social do contrato; b) sustentando, concomitantemente, a equivalência de ambos.

\section{CONCLUSÃO}

À guisa de conclusão, pode-se inferir que, na senda do movimento da constitucionalização do Direito Civil, o novo Código Civil recepcionou essa perspectiva, deslocando o seu fundamento axiológico, da tradicional liberdade irrestrita e a absolutização do patrimônio, para a proteção da dignidade humana e valorização da solidariedade social. O reflexo disso, no campo do Direito Civil, foi a incorporação, no diploma de 2002, de dispositivos que sinalizam esse objetivo, entre eles, a função social do contrato, dando abrigo legal à polêmica doutrinária que perdura há séculos, perpassando as discussões gregas sobre o voluntarismo humano, até os questionamentos hodiernos sobre a limitação do direito de contratar face aos interesses sociais.

A expressão "utilidade social", ou "ordem pública", como faz constante alusão a doutrina, diz pouco, ou quase nada, aos magistrados que são obrigados legalmente a regular a vida social, provendo tutela jurisdicional adequada à população. É nessa situação que o papel dos pesquisadores se impõe, determinando os limites dentro dos quais se poderá aplicar o princípio da função social do contrato, auxiliando a fundamentação dos magistrados e implementando a segurança jurídica.

A pesquisa estatística de determinados acórdãos remete à conclusão de que os magistrados têm, amiúde, por falta de produção doutrinária disponível (ou, quiçá, por outras razões subjetivas que refogem à percepção do autor deste artigo), fundamentado suas decisões de forma confusa. Por certo que as intenções de concretizar a justiça do caso concreto são louváveis, corroborando a noção do homem como animal metafísico schopenhaueriano ${ }^{44}$, contudo, não se pode comprometer um ideal - o da segurança jurídica, da parte que saiu desfavorecida da decisão judicial - em prol de outro, às custas da imprecisão científica. 
Constata-se, deveras, pela prática reiterada dos Tribunais, uma virtual revogação, a retirada da vox própria, do princípio da função social, quando se justifica sua aplicação tão-somente associada a outros princípios. Repetimos: cabendo à doutrina o papel de desenvolver os âmbitos de aplicação da função social do contrato, não pode o magistrado ignorar suas características peculiares, levando em conta similitude de seus efeitos, reduzindo a incidência do artigo 421 à coadjuvação com os demais princípios já consagrados, como o da boa-fé.

Se há relação entre os princípios, inobservância comum a eles, destaque-se na fundamentação, sob pena de estar-se privilegiando o valor da justiça em detrimento da segurança jurídica da comunidade. Se a solidariedade social e a dignidade humana são valores a ser preservados em uma sociedade, amparando os que se sentem lesados pelas contingências temporais do contrato, também estes princípios devem oferecer esteio àquele que teve seu direito lesado, e que não sabe se, em distinta situação, outro princípio a ser invocado comprometerá outra de suas relações contratuais.

É nesse sentido que pretendemos ter demonstrado, atendendo às propostas aventadas no início destas páginas, a correlação entre o instituto jurídico da função social do contrato e a demanda pública por segurança jurídica, através da fundamentação dos atos decisórios do Poder Judiciário.

\section{LE "RETRAIT" DU PRINCIPE DE LA FONCTION DE CONTRAT SOCIAL: RÉFLEXIONS SUR LA MISE EN OEUVRE DE L'ARTICLE 421 DU CODE CIVIL JURISPRUDENTIELLE ET SON INTERFACE AVEC LE DEVOIR DE MOTIFS DES ARRETS}

\section{RÉSUMÉ}

Cet article a pour but d'établir un rapport entre le principe de la fonction sociale du contrat, exprimé dans l'article 421 du Code Civil brésilien, son application jurisprudentiel et le devoir constitutionel de fondamentation des decisions judiciaires. La première partie analyse le développement historique et dogmatique du principe de la fonction sociale du contrat, au même temps qu'examine l'événement de l'État sociale et les modifications dans la structure principiologique traditionnelle du contrat. L'auteur étudie le contenu philosophique du article 421, à l'égard des principes de la solidarité sociale et la socialité, à cause de son assujettissement à la Constitution de 1988 et au Code Civil de 2002. La deuxième partie s'agit d'un equisse de definition, à partir des characteristiques principaux du principe de la fonction sociale du contrat, surtout ses perspectives intérieur et extérieur. Finalement, dans la troisième partie il faut voir les decisions des tribunaux pour que nous puissions remarquer s'ils ont contribué avec la definition du principe et s'ils ont bien expliqué leurs arguments en l'utilisant.

MOTS-CLÉS : Devoir de la fondamentation. Fonction Sociale du Contrat. Jurisprudence. Principes Contractuels. 


\section{THE REVOCATION OF CONTRACT'S SOCIAL FUNCTION: THOUGHTS ABOUT THE JURISPRUDENTIAL APPLICATION OF THE CIVIL CODE ARTICLE 421 AND ITS INTERFACE WITH THE JUDICIAL DECISION GROUNDING DUTY}

\section{ABSTRACT}

This article tries to establish the relationship between the social function principle, visible on Civil Code article 421, its jurisprudential application and the judicial decision grounding duty. The first part will focus on the historic-dogmatic configuration of the social function principle, throughout the transition between liberal and social Estate, and focusing on changes that arouse on contract's principles. The author analyses the possible relationship on the article 421 philosophical center in conjunction with the social solidarity principle - it should be noted that such principle is inserted in 1988's Brazil Federal Constitution and the present Civil Code legal content. The second part delimitate the mainly characters of the contract social function, on its internal and external perspectives. By the end, the third part will analyze the newly jurisprudence of the Brazil mainly courts and how their actions with bigger or lesser scientific approach - set the definition of contract social function and became lawful with the due legal grounding.

Keywords: Contract's social function. Contractual principles. Grounding duty. Jurisprudence.

\section{NOTAS}

1 Rogério Gesta Leal é Desembargador do Tribunal de Justiça do Estado do Rio Grande do Sul, Doutor em Direito, Professor Titular do Mestrado e Doutorado em Direito da Universidade de Santa Cruz do Sul, Professor Colaborador da Universidade Estácio de Sá. Professor Visitante da Università Túlio Ascarelli - Roma Trè, Universidad de La Coruña - Espanha, e Universidad de Buenos Aires. Professor da Escola Nacional de Formação e Aperfeiçoamento da Magistratura ENFAM. Membro da Rede de Direitos Fundamentais-REDIR, do Conselho Nacional de JustiçaCNJ, Brasília. Coordenador Científico do Núcleo de Pesquisa Judiciária, da Escola Nacional de Formação e Aperfeiçoamento da Magistratura - ENFAM, Brasília. E-mail: rleal@unisc.br. Endereço: Universidade de Santa Cruz do Sul, Curso de Direito, Mestrado em Direito - Avenida Independência, 2293 - Universitário - CEP 96815-900 - Santa Cruz do Sul, Brasil - Caixa Postal: 188.

2 O autor é graduando na Faculdade de Direito da Universidade Federal do Rio Grande do Sul. É pesquisador bolsista (FAPERGS) junto ao grupo de pesquisa "A Arbitragem como meio de solução de controvérsias", sob a orientação da professora doutora Véra Maria Jacob de Fradera. E-mail: brunoleal88@hotmail.com. Endereço: Faculdade de Direito da UFRGS - Avenida João Pessoa, 80 - CEP 90040-000 - Porto Alegre-RS, Brasil.

3 Este é o depoimento do professor Galgano:"All'autonomia contrattuale sono oggi dischiuse frontiere in passato impensabili. Il contratto era, nella sua concezione classica, lo strumento per comporre interessi particolari; oggi il contratto fra privati prende il posto della legge in motli settori della vita sociale.Si spinge fino a sostituirsi ai pubblici poteri nella protezione di interessi generali, propri dellintera collettività, qual è stato, dapprima, l'interesse dei consumatori, che i meccanismi di autodisciplina hanno difeso contro gli inganni pubblicitari.[..] La forza vincolante del codice di autodisciplina o degli organismi rappresentativi ha fonte contrattuale: deriva, nei confronti dei mezzi pubblicitari, dall'adesione di queti o dei loro organismo rappresentativi all'associazione che ha dettato il codice". In GALGANO, Francesco. La Globalizzazione nello specchio del diritto. Bologna: il Mulino, 2005..99-102 passim. (grifos nossos)..

4 "O direito das coisas e o direito ao crédito representam, no mundo jurídico, por assim dizer, matéria e força: o direito das coisas é o elemento do mundo jurídico em repouso; o direito ao crédito é o elemento em movimento.[...] Por essa razão, a vida jurídica tem caráter estático 
sempre que, preferencialmente, funda-se no direito das coisas; contudo, possui caráter dinâmico sempre que o direito ao crédito constitui seu principal fundamento". Vide RADBRUCH, Gustav. Filosofia do Direito. Traduzido por Marlene Holzhausen. São Paulo: Martins Fontes, 2004.p.209.

5 Vide MARTINS-COSTA, Judith. Notas sobre o princípio da função social dos contratos. Em texto disponível no site <http://www.realeadvogados.com.br/pdf/judith.pdf>, p. 4. Acesso em 28/10/2007.

6 "Passemos agora às obrigações. Obrigação é o vínculo de direito, formado segundo o nosso direito civil, que nos coage a pagar alguma coisa. [...] Uma divisão subseqüente classifica-as em quatro espécies, segundo nascem de um contrato, de um quase-contrato (quasi contracto), de um delito, ou de um quase-delito (quasi delicto)". Vide FLAVIUS PETRUS SABBATIUS JUSTINIANUS. Institutas do Imperador Justiniano. Traduzido por José Cretella Jr. e Agnes Cretella. 2.ed. São Paulo: RT, 2005. p. 185.

7 Nos contratos, diante do elemento objetivo, o acordo de vontade (elemento subjetivo) é mero pressuposto de fato, colocado em segundo plano. Importa a correspondência desse acordo de vontade com um negócio jurídico previamente reconhecido pelo direito objetivo e a que este reconheça validade e eficácia. Para estes comentários consultei ALVES, José Carlos Moreira. Direito Romano. 5.ed. Rio de Janeiro: Forense, 1995. p. 127. Tomo II.

8 "O consensualismo é tanto mais facilmente admitido a partir do fim da Idade Média quanto é certo que o individualismo suplanta a concepção comunitário do Direito. As comunidades clânicas, aldeãs ou mesmo familiares desapareceram quase inteiramente, sobretudo nas cidades; daqui em diante, é o homem, enquanto indivíduo isolado, livre, com capacidade de dispor de sua pessoa e dos seus bens, que constitui o sujeito de direito. No domínio dos contratos, o individualismo traduz-se sobretudo pela autonomia da vontade". Vide GILISSEN, John. Introdução Histórica ao Direito. Traduzido por A.M. Hespanha. 4.ed. Lisboa: Calouste Gulbenkian, 2003. p.738.

9 "Il y a un moment essentiel dans l'histoire du droit, ou de la pensée juridique, auquel on n'accorde pas toujours la grande attention qu'il mérite : celui de la scolastique tarvide, de la scolastique franciscaine de Duns Scott ou Guillaum D'Occam. [...]Le volontarisme juridique n'est-il pas tout entier déjà dans cette rupture avec le droit naturel d'Aristote ? Car une foi brisée la croyance au droit naturel, il n'est plus de droit que positif (divin ou humain), tour droit relève de l'institution. Si l'individu se trouve libre au point de départ, rien ne peut le lier que son consentement. Désormais, l'unique origine des règles de droit c'est l'accord de plusieurs volontés. On sait le succès de cette doctrine. Hobbes, Pufedorf, Locke, Thomasius, sur sa base, ont renouvelé touta la théorie du droit ». Vide VILLEY, Michel. Essor et Décadence du Volontarisme Juridique. In : Leçons d'Histoire de la Philosophie du Droit. Paris : Dalloz, 1962. p. 273-4.

10 "Contrato é um conceito jurídico: uma construção da ciência jurídica elaborada (além do mais) com o fim de dotar a linguagem jurídica de um termo capaz de resumir, designando-os de forma sintética, uma série de princípios e regras de direito, uma disciplina jurídica complexa. Mas como acontece com todos os conceitos jurídicos, também o conceito de contrato não pode ser entendido a fundo, na sua essência íntima, se nos limitarmos a considerá-lo numa dimensão exclusivamente jurídica - como se tal constituísse uma realidade autônoma, dotada de autônoma existência nos textos legais e nos livros de direito. Bem pelo contrário, os conceitos jurídicos -e entre estes, em primeiro lugar, o de contrato - refletem sempre uma realidade exterior a si próprio, uma realidade de interesses, de relações, de situações econômico-sociais, relativamente aos quais cumprem, de diversas maneiras, uma função instrumental" Vide os preciosos comentários de ROPPO, Enzo. O Contrato. Traduzido por Ana Coimbra. Coimbra: Almedina, 1988. p.7.

11 WIEACKER, Franz. História...op.cit. p. 332.

12 Para interessante ensaio sobre o desenvolvimento e decadência da plena liberdade contratual, de onde retiramos a expressão, vide MARTINS-COSTA, Judith. A noção de contrato na história dos pactos. In: Homenagem a Carlos Henrique de Carvalho: o editor dos juristas. São Paulo: RT, 1995. p.33.

13 ZIPPELIUS, Reinhold. Teoria Geral do Estado. 3.ed. Traduzido por J.J.Gomes Canotilho. Lisboa: Fundação Calouste Gulbenkian, 1997. p. 462-476 passim.

14 GALGANO, Francesco. II diritto privato fra Codice e Constituzione. Bolonha, 1978. p.129.

15 É no nome de Josserand que aparece, pioneiramente, no início do século XX, uma análise crítica do absolutismo da vontade e da plena autonomia no exercício de direitos. Em suas obras principais (De l'abus des droits e De la relativité des droits e leurs relativité), defende o autor uma função ínsita a qualquer direito, fora da qual o seu exercício seria abusivo e injustificável. Vide JOSSERAND, Louis. De L'abus des Droits. Paris : Arthur Rousseau, 1905. 
16 Na análise do contrato, Cimbali procede a diferentes visões do mesmo fenômeno: na perspectiva de sua constituição, sim, prevalece a vontade individual; com relação à sua eficácia, é impossível dissociá-la de uma expressão da necessidade social. A vontade subjetiva de um deve, necessariamente, adaptar-se à vontade objetiva do todo. Vide CIMBALI, Enrico. La Funzione Sociale dei Contratti. In: Opere Complete.Studi di Diritto Civili. 2.ed. Torino: Unione Tipografico, 1900

17 Karl Renner apela para uma percuciente análise sociológica, remetendo às raízes antropológicas do homem, que obedece determinadas leis naturais de boa convivência porquanto compreende, empiricamente, que fora delas, resta nada mais do que a extinção de sua espécie. Na senda desse espírito gregário, o mesmo respeito empírico a essas leis naturais transporta-se para as leis sociais, razão pela qual se constata uma premência da "vontade social" à "vontade individual". Vide RENNER, Karl. The Institutions of Private Law and their social functions. Traduzido por Agnes Schwarzschild. Londres: Routledge \& Kegan Paul Ltd., 1949.

18 "De fato, o processo de publicização do privado é apenas uma das faces do processo de transformação das sociedades industriais mais avançadas. Ele é acompanhado e complicado por um processo inverso que se pode chamar de 'privatização do público'. [...]Os dois processos, de publicização do privado e de privatização do público, não são de fato incompatíveis, e realmente compenetram-se um no outro. O primeiro reflete o processo de subordinação dos interesses do privado aos interesses da coletividade representada pelo Estado que invade e engloba progressivamente a sociedade civil; o segundo representa a revanche dos interesses privados através da formação dos grandes grupos que se servem dos aparatos públicos para o alcance dos próprios objetivos". Vide BOBBIO, Norberto. Estado, Governo, sociedade. Por uma teoria geral da Política. Traduzido por Marco Aurélio Nogueira. Rio de Janeiro: Paz e Terra, 1987. p. 267. (grifos nossos).

19 "A autonomia privada exige ser compreendida de modo funcional: seja no campo da dignidade da pessoa humana, seja no campo econômico em sentido estrito [...]Ocorre que a incidência dos princípios constitucionais funcionaliza o conceito, vale dizer, a própria compreensão genética da autonomia privada. Por sua vez, os chamados limites à autonomia privada ou funcionalizam o exercício desse poder jurídico ou o exclui, no caso concreto". Vide SILVA, Jorge Cesa Ferreira da. Princípios de direito das obrigações no novo Código Civil. In: SARLET, Ingo Wolfgang. (org.). $O$ Novo Código Civil e a Constituição. Porto Alegre: Livraria do Advogado, 2003. p.106. (grifos nossos). Nesse mesmo sentido, escreve a professora MARTINS-COSTA, Judith Hofmeister: " $A$ liberdade é valor fundante, decorrência do reconhecimento da dignidade da pessoa humana a quem se reconhece, pré-juridicamente, a auto-determinação.[...]. O problema está no modo de entender-se a liberdade. Não se trata, ao meu ver, nem de uma liberdade consentida, nem de uma liberdade exercida no vazio, mas de uma liberdade situada, a liberdade que se exerce na vida comunitária, isto é: o lugar onde imperam as leis civis. [...] Daí a imediata referência, logo após a liberdade de contratar, à função social do contrato; daí a razão pela qual liberdade e função social se acham entretenidos, gerando uma nova idéia, a de autonomia (privada) solidária”. Em Reflexões sobre o princípio da Função Social dos Contratos. In: CUNHA, Alexandre dos Santos. (coord.). O Direito da Empresa e das Obrigações e Novo Código Civil. São Paulo: Quartier Latin, 2006. p.223. (grifos nossos).

20 Conferir, na íntegra, TEPEDINO, Gustavo. Premissas Metodológicas para a constitucionalização do Direito Civil. In: Temas de Direito Civil. Rio de Janeiro: Renovar, 2006. p.7. Ainda nesse sentido NETO, Eugênio Facchini. Reflexões Histórico-evolutivas sobre a Constitucionalização do Direito Privado. In: SARLET, Ingo Wolfgang. (org.) Constituição, Direitos Fundamentais e Direito Privado. 2.ed. Porto Alegre: Livraria do Advogado, 2006. p. 28-35. passim. (grifos nossos).

21 Alguns outros autores enxergam a relação da função social do contrato com o princípio da dignidade humana (encartado no artigo 1ํ, III da Constituição Federal), como FILHO, Eduardo Tomasevicius. A função social do contrato: conceito e critérios de aplicação. In: CUNHA, Alexandre dos Santos. (coord.). O Direito da Empresa e das Obrigações e Novo Código Civil. São Paulo: Quartier Latin, 2006. p. 200.

22 SILVA, Luis Renato Ferreira da. A função social do contrato no Novo Código Civil e sua conexão com a solidariedade social. In: SARLET, Ingo Wolfgang. (org.). O Novo Código Civil e a Constituição. Porto Alegre: Livraria do Advogado, 2003. p.132.

23 NORONHA, Fernando. O Direito dos Contratos e seus Princípios Fundamentais. São Paulo: Saraiva, 1992.

24 MARTINS-COSTA, Judith. BRANCO, Gerson Luiz Carlos. Diretrizes Teóricas do Novo Código Civil Brasileiro. São Paulo: Saraiva, 2002. p. 67. Ainda neste sentido MARTINS-COSTA, Judith. O novo Código Civil Brasileiro: em busca da ética da situação. In: Cadernos do Programa de Pós- 
Graduação em Direito - PPGDir./UFRGS. Edição Especial. V. 2, n.4 (jun. 2004). Porto Alegre: PPGDir./UFRGS, 2004. p. 630.

25 A denominação é da professora Judith Martins-Costa em O novo Código Civil brasileiro: em busca da ética da situação...op.cit. p. 584.

26 A nomenclatura da distinção (entre eficácias intersubjetiva/interna e transubjetiva/externa) é corroborado por certo setor da doutrina, a que remetemos os comentários da professora MARTINS-COSTA, Judith. Reflexões sobre o princípio da Função Social dos Contratos. In: CUNHA, Alexandre dos Santos. (coord.). O Direito da Empresa e das Obrigações e Novo Código Civil. São Paulo: Quartier Latin, 2006. p. 237-248 passim.

27 MARTINS-COSTA, Judith. Reflexões...op.cit. p. 238.

28 NEGREIROS, Teresa. Teoria do Contrato. Novos Paradigmas. Rio de Janeiro: Renovar, 2002. p. 398-503 passim.

29 E é nesse sentido que posso entender as observações do professor Calixto Salomão Filho, quando escreve que a função social do contrato visaria proteger os interesses institucionais. Vide Função Social do Contrato: Primeiras Anotações. In: Revista de Direito Mercantil. n.132. p. 7-24 MARTINS-COSTA, Judith. Reflexões...op.cit. p. 241.

31 MARTINS-COSTA, Judith. Reflexões...op.cit. p. 243.

32 NEGREIROS, Teresa. Teoria do Contrato...op.cit. p. 241

33 AZEVEDO, Antônio Junqueira de. Princípios do Novo Direito Contratual e Desregulamentação do Mercado, Direito de Exclusividade nas Relações Contratuais de Fornecimento, Função Social do Contrato e Responsabilidade Aquiliana do Terceiro que Contribui para o Inadimplemento Contratual. In: Revista dos Tribunais. n. 750. São Paulo: RT, 2000. p. 11-17. MARTINS-COSTA, Judith. Reflexões...op.cit. p. 245.

35 MARTINS-COSTA, Judith. Reflexões...op.cit. p. 248.

36 BARROSO, Lucas Abreu. A função ambiental do contrato. In: DELGADO, Mário Luiz. ALVES, Jones Figueiredo. (coord.) Questões Controvertidas no direito das obrigações e dos contratos. São Paulo: Método, 2005. p. 291.

37 Para as consultas jurisprudenciais foram utilizados os sites: www.sti.gov.br, www.ti.rs.gov.br, www.ti.sc.gov.br, www.ti.sp.gov.br, www.tiri.gov.br. Data de acesso: 15/04/2008.

38 Vide LEAL, Mônia Clarissa Hennig. Estado de Direito. In: BARRETO, Vicente de Paula. Dicionário de Filosofia do Direito. São Leopoldo: Unisinos, 2006.

"Poder significa a possibilidade de impor a própria vontade, dentro de uma relação social, ainda que contra qualquer resistência, e qualquer que seja o fundamento dessa possibilidade". Vide WEBER, Max. Dominação. In: F.H.Cardoso e C.E. Martins (orgs.). Política e Sociedade. São Paulo: Nacional, 1983. P. 17. Volume I

"A dominação racional-legal, por sua vez, já conta com um certo grau de justificação e fundamentação do Poder exercido, que se localiza, exatamente, no direito estatuído de modo racional, com pretensão de ser respeitado pelos membros da associação. Este plexo normativo vai delimitar, ao menos genericamente, as possibilidades do exercício do Poder, imprimindo-Ihe caracteres e feições racionais tendo como parâmetro validativo a norma legal. Aqui, há uma dominação e exercício do poder de forma impessoal, pois, quem obedece, não o faz em relação à pessoa do soberano, mas em face do direito e na condição de membro de uma associação. Por tais razões é que, na modernidade, o exercício do poder e da autoridade racional dependem de estruturas administrativo-burocráticas impessoais, hierarquizadas e profissionais. Assim é que, a partir deste último modelo de dominação e poder, todo e qualquer ato de imposição de vontade se baseia no pressuposto e condição de que os indivíduos que obedecem o fazem, em média, porque consideram obrigatória, também subjetivamente, a relação de dominação". Vide LEAL, Rogério Gesta. O Estado-juiz na democracia contemporânea. Uma perspectiva procedimentalista. Porto Alegre: Livraria do Advogado, 2007.p.12. grifos nossos.

41 PONTES DE MIRANDA, Francisco Cavalcanti. Tratado de Direito Privado. Rio de Janeiro: Borsoi, 1955. p. 9-10. Tomo V.

42 No mesmo sentido encaminham-se diversos outros, aos quais remetemos: TJSC - Apelação Cível 2005.020801-0 - Des. Sérgio Izidoro Heil - 30/09/2005; TJRS - Apelação Cível № 70020237178 Décima Segunda Câmara Cível - Des. Dálvio Leite Dias Teixeira - 06/09/2007; TJRJ - Apelação Cível 2007.001.00581 - Des. Edson Scisinio Dias - Décima Quarta Câmara Cível - 03/10/2007; TJRJ - 2007.001.31145 - Apelação Cível - Des. Gilberto Rego - Sexta Câmara Cível - 29/08/2007.

43 MAXIMILIANO, Carlos. Hermenêutica e Aplicação do Direito. 19. ed. Rio de Janeiro: Forense, 2002. p.91. 
44 Afirma Arthur Schopenhauer que o homem é o único animal metafísico, porquanto lança mão de razões racionais para comportamentos cujas reais origens fogem à razão. Nesse sentido, é possível observar que, nas decisões em que se peca pela confusão doutrinária, os juízes acabam cedendo a um impulso não-racional (de concretizar a justiça no caso concreto) em detrimento da rigidez científica. Vide SCHOPENHAUER, Arthur. $O$ mundo como vontade e como representação. São Paulo: Unesp, 2005. p. 54-5.

\section{REFERÊNCIAS}

ALVES, José Carlos Moreira. Direito Romano. 5. ed. Rio de Janeiro: Forense, 1995. Tomo II.

AZEVEDO, Antônio Junqueira de. Princípios do Novo Direito Contratual e Desregulamentação do Mercado, Direito de Exclusividade nas Relações Contratuais de Fornecimento, Função Social do Contrato e Responsabilidade Aquiliana do Terceiro que Contribui para o Inadimplemento Contratual. In: Revista dos Tribunais. n. 750. São Paulo: RT, 2000.

BARROSO, Lucas Abreu. A função ambiental do contrato. In: DELGADO, Mário Luiz. ALVES, Jones Figueiredo. (coord.) Questões Controvertidas no direito das obrigações e dos contratos. São Paulo: Método, 2005.

BOBBIO, Norberto. Estado, Governo, sociedade. Por uma teoria geral da Política. Traduzido por Marco Aurélio Nogueira. Rio de Janeiro: Paz e Terra, 1987.

CIMBALI, Enrico. La Funzione Sociale dei Contratti. In: Opere Complete.Studi di Diritto Civili. 2.ed. Torino: Unione Tipografico, 1900.

FILHO, Eduardo Tomasevicius. A função social do contrato: conceito e critérios de aplicação. In: CUNHA, Alexandre dos Santos. (coord.). O Direito da Empresa e das Obrigações e Novo Código Civil. São Paulo: Quartier Latin, 2006.

GALGANO, Francesco. La Globalizzazione nello specchio del diritto. Bologna: il Mulino, 2005. Il diritto privato fra Codice e Constituzione. Bolonha, 1978

GILISSEN, John. Introdução Histórica ao Direito. Traduzido por A.M. Hespanha. 4.ed. Lisboa: Calouste Gulbenkian, 2003 .

JOSSERAND, Louis. De L'abus des Droits. Paris : Arthur Rousseau, 1905.

LEAL, Mônia Clarissa Hennig. Estado de Direito. In: BARRETO, Vicente de Paula. Dicionário de Filosofia do Direito. São Leopoldo: Unisinos, 2006.

LEAL, Rogério Gesta. O Estado-juiz na democracia contemporânea. Uma perspectiva procedimentalista. Porto Alegre: Livraria do Advogado, 2007

MARTINS-COSTA, Judith. BRANCO, Gerson Luiz Carlos. Diretrizes Teóricas do Novo Código Civil Brasileiro. São Paulo: Saraiva, 2002.

. O novo Código Civil Brasileiro: em busca da ética da situação. In: Cadernos do Programa de Pós-Graduação em Direito - PPGDir./UFRGS. Edição Especial. V. 2, n.4 (jun. 2004). Porto Alegre: PPGDir./UFRGS, 2004.

Reflexões sobre o princípio da Função Social dos Contratos. In: CUNHA, Alexandre dos Santos. (coord.). O Direito da Empresa e das Obrigações e Novo Código Civil. São Paulo: Quartier Latin, 2006.

MAXIMILIANO, Carlos. Hermenêutica e Aplicação do Direito. 19. ed. Rio de Janeiro: Forense, 2002. 
NETO, Eugênio Facchini. Reflexões Histórico-evolutivas sobre a Constitucionalização do Direito Privado. In: SARLET, Ingo Wolfgang. (org.) Constituição, Direitos Fundamentais e Direito Privado. 2.ed. Porto Alegre: Livraria do Advogado, 2006.

NORONHA, Fernando. O Direito dos Contratos e seus Princípios Fundamentais. São Paulo: Saraiva, 1992.

PONTES DE MIRANDA, Francisco Cavalcanti. Tratado de Direito Privado. Rio de Janeiro: Borsoi, 1955. Tomo V.

RADBRUCH, Gustav. Filosofia do Direito. Traduzido por Marlene Holzhausen. São Paulo: Martins Fontes, 2004.

RENNER, Karl. The Institutions of Private Law and their social functions. Traduzido por Agnes Schwarzschild. Londres: Routledge \& Kegan Paul Ltd., 1949.

SCHOPENHAUER, Arthur. O mundo como vontade e como representação. São Paulo: Unesp, 2005.

SILVA, Jorge Cesa Ferreira da. Princípios de direito das obrigações no novo Código Civil. In: SARLET, Ingo Wolfgang. (org.). O Novo Código Civil e a Constituição. Porto Alegre: Livraria do Advogado, 2003.

SILVA, Luis Renato Ferreira da. A função social do contrato no Novo Código Civil e sua conexão com a solidariedade social. In: SARLET, Ingo Wolfgang. (org.). O Novo Código Civil e a Constituição. Porto Alegre: Livraria do Advogado, 2003.

TEPEDINO, Gustavo. Premissas Metodológicas para a constitucionalização do Direito Civil. In: Temas de Direito Civil. Rio de Janeiro: Renovar, 2006.

VILLEY, Michel. Essor et Décadence du Volontarisme Juridique. In: Leçons d'Histoire de la Philosophie du Droit. Paris: Dalloz, 1962.

WEBER, Max. Dominação. In: F.H.Cardoso e C.E. Martins (orgs.). Política e Sociedade. São Paulo: Nacional, 1983. Volume I.

ZIPPELIUS, Reinhold. Teoria Geral do Estado. 3.ed. Traduzido por J.J.Gomes Canotilho. Lisboa: Fundação Calouste Gulbenkian, 1997

Recebido para publicação: 16/06/2010

Aceito para publicação: 27/12/2010 